Dynamic and statistical aspects of the class of simple ideal metabolic networks and the ecological network consists of such networks under the fluctuating resource supply are investigated. The ultimate goal of this investigation is to uncover the relation between two variational principles, the second law of thermodynamics and Darwin's theory of evolution.

We systematically construct simple reaction systems that describe ideal metabolic processes by thermodynamically reversible catalytic reaction networks consists of a few chemical components (catalysts) with inflow of resource chemical and outflow of waste chemical. First, we evaluate the metabolic performance of each reaction network by measuring the steady reaction flux and the response under strong and weak inflow of resource and the relaxation to thermodynamic equilibrium state under no supply of resource. Here, we found that the reaction networks involving the negative correlation of catalytic relations tend to exhibit the robust and high reaction flux.

Second, we consider the ecological system consists of the above ideal metabolic networks where they mutually suppress their activities with each other through the competition of a resource. By the simulation of this system under the fluctuating condition where the amount of the resource supply varies periodically, we found that which network can sustain its activity depends strongly on not only the period of the resource supply but also the history of the variations of the period.

\section{P290 原始地球の熱水環境における修飾海水からのアミノ酸の重合}

Prebiotic oligomerization of amino acids with modified seawater under the hydrothermal environments in primitive earth.

Satoshi Shida, Ayaka Sugai, Hideaki Takehana, Eiichi Imai, Hajime Honda, (Department of Bioengineering, Nagaoka University of Tecnology)

In primitive earth, organic compound with low molecular weight must be oligomerized by the energy from natural environment to form some kinds of functional high molecular weight molecules. One of the plausible candidate should be the hydrothermal vent under deep sea where seawater containing a tough amount of metal ions in addition with amino acids, nucleic acids or other biologically-relevant molecules erupted from volcano at high temperature into cold seawater. We have been focusing on the process of quenching when the unstable large molecule with some biological function might have survived by soaking into cold aqueous milieu.

Modified seawater containing five types of amino acids with $\mathrm{Fe}, \mathrm{Cu}, \mathrm{Mn}, \mathrm{Mo}$ $\mathrm{Ca}, \mathrm{Na}, \mathrm{K}$ and $\mathrm{Cl}$ was reacted with a flow reactor simulating a hydrothermal vent. By using the reactor, we have succeeded to form glycine oligomers even in aqueous solution. The five amino acids were found to make several mixed oligomers detected by HPLC. Some of the produced oligomers have strong fluorescent emission which was found to increase as the development of a reaction within the reactor. Among the product molecule, some molecules which have the capacity to inhibit the degradation of glycine tetramers was found. The results should indicate that the environmental conditions of not only hydrothermal vent but also component of modified seawater would have a contribution for making a functional oligomers relevant for the emergence of life.

\section{$1 \mathrm{P} 291$ 遺伝子の自己複製反応に与える反応場サイズ依存性 \\ $1 H 1325$ Effects of cell size on internal self-replication of genetic infor- mation}

Yohsuke Bansho ${ }^{1}$, Norikazu Ichihashi ${ }^{2}$, Tomoaki Matsuura ${ }^{2}$, Tetsuya Yomo ${ }^{1,2.3},\left({ }^{1}\right.$ Frontier Biosciences, Osaka Univ.: ${ }^{2}$ Information Science and Technology, Osaka Univ.: ${ }^{3}$ ERATO, JST)

Living systems consists of many biochemical reactions performed in microscale compartments, cells. What effect does the size have on the internal reactions? We focused on the relationship between the size of cell-like compartment and the internal self-replication of genetic information.

We used w/o emulsions as cell-like compartments, which are small droplets of water dispersed in oil. First, we constructed a size-separating device using $\mu$ TAS technique that allowed us to separate the emulsions depending on the diameter into five fractions: $2,3,6,12$, and $16 \mu \mathrm{m}$ on average.

Second, we constructed a self-replication system of genetic information composed of a template RNA encoding RNA replicase and a cell-free translation system. RNA replicase was translated from the template RNA, and then replicated the template RNA. The self-replication, however, stopped after few rounds of replication because of the appearance of a parasitic RNA, a small RNA lacking the RNA replicase coding region and amplified enormously resulting in competitive inhibition of template RNA replication.

We found that the amplification of parasitic RNA was repressed and that of template RNA was slightly increased in smaller emulsions. These results were explained as follows. The parasitic RNA was confined in minor fractions of the droplets so that the other major fractions were free from the parasite, and thus amplification of template RNA enhanced in the smaller emulsions. This result suggests that cell size can be a critical parameter of an internal reaction.

\section{$1 P 292$ ドメインリンカーの構造と配列が構造ドメイン形成に及ぼす影 響}

Influence of Domain Linker Sequence and Structure on the Definition of Structural Domains.

Teppei Ebina, Shun Iwasaki, Yutaka Kuroda, (Department of Biotechnology and Life Science, Tokyo University of Agriculture and Technology, 12-24-16 Naka-machi, Koganei-shi, Tokyo 184-8588, Japan)

We report the influence of domain linker's structures and sequences on our definition of stable structural domains. In our definition, structural domains are domains that have no inter-domain contacts as evaluated using the atomic coordinates of the whole protein. The dataset used in the present study comprised 27 protein sequences that contain one domain linker separating two adjacent structural domains and that have at least one protein sequence homolog in the PDB with a fully conserved domain linker sequence.

The analysis demonstrated that the dataset can be divided into two parts: (1) 13 proteins in which the structural domain definition was conserved throughout the homolog PDB structures/sequences; and (2) 14 proteins in which the definition of structural domains depended on which PDB structure was used. We found that the amino acid composition of domain linkers in the first groups was different from that in the second groups. In particular we observed that prolines were over-represented in the second group. In addition, the RMSD of most domain linker regions in both groups were less than $0.5 \AA$ (average of $\sim 0.2 \AA$ ). Furthermore, we observed, for many proteins, that the RMSD among homologous domains in the second group were larger than in the first group. In the poster we will discuss possible implication of these observations on the inter- and intra-domain motions.

\section{P293 Modeling of 3R complexes from structure database}

Kouta Mayanagi ${ }^{1}$, Mihoko Saito ${ }^{2}$, Takuji Oyama ${ }^{3}$, Yoshizumi Ishino ${ }^{1}$, Tsuyoshi Shirai ${ }^{2},\left({ }^{1}\right.$ Kyusyu University: ${ }^{2}$ Nagahama Institute of Bioscience and Technology: ${ }^{3}$ Osaka University)

The computer system SIRD (Structure-Interaction Relational Database), which processes 2ry database of PDB by automatically classifying structures and interactions, has been developed. SIRD database can be used to infer protein complex structures by compiling the known structures. This system was applied to construct several 3R (Replication, Repair, and Recombination) complexes, for which no experimental structures were known, and the models from SIRD system were examined by solving the complex structures with $\mathrm{X}$-ray crystallography and single-particle electron microscopy. The models revealed good agreement with the experimental structures. Especially, the models of ternary complex of DNA polymerase B-PCNA(clamp)-DNA predicted the presence of two different (polymerizing and editing) modes of this complex. A close inspection of the model suggested a conserved Glu residue of PCNA was important for the functional mode switch during DNA replication.

$1 P 294$

タンパク質-リガンド相互作用の共通性と多様性 : 混合正規分 布推定による PDB からのデータマイニング

Conservation of protein-ligand interactions: a data-mining of the PDB by using Gaussian mixture model

Kota Kasahara ${ }^{1}$, Kengo Kinoshita ${ }^{2,3}$, Toshihisa Takagi ${ }^{1,4,5},\left({ }^{1}\right.$ Grad. Sch. of Frontier Sci., Univ. of Tokyo: ${ }^{2}$ Grad. Sch. of Info. Sci., Tohoku Univ.: ${ }^{3}$ JST-BIRD: ${ }^{4}$ DBCLS: ${ }^{5}$ National Inst. of Genetics)

Proteins conduct versatile molecular functions through recognition of their specific ligands. Understanding of the specific ligand recognition of proteins is one of main subjects in the biophysics. Since the specificity is arisen from chemical and geometrical complementarities that stabilize a complex by intermolecular interactions, analysis of the inter-molecular interactions based on 3D structure data of protein-ligand complexes is quite important.

In this field, structure comparison methods for binding sites of proteins have been studied. They have elucidated several structural patterns in the binding sites called "binding motifs" that play important roles on the ligand recognition. However, these methods cannot directly treat inter-molecular interactions since they have focused only on the protein structures. In order to investigate the patterns of interactions, both of protein and ligand structures should be considered.

We have carried out a data-mining for the inter-molecular interactions in protein-ligand complexes. Spatial distributions of interactions between protein and ligand fragments were collected from a database. And then, Gaussian mixture models were constructed from the spatial distributions in order to obtain the patterns of interactions as a Gaussian component. As a result, the interaction patterns that were conserved among several proteins have been obtained. Moreover, some of them were conserved among proteins with distinct 